\title{
Microbial Ecology in Health and Disease
}

\section{Enhanced Growth of Complex Communities of Dental Plaque Bacteria in Mucin-Limited Continuous Culture}

\section{A. Glenister, Katja E. Salamon, K. Smith, D. Beighton \& C. W. Keevil}

To cite this article: D. A. Glenister, Katja E. Salamon, K. Smith, D. Beighton \& C. W. Keevil (1988) Enhanced Growth of Complex Communities of Dental Plaque Bacteria in Mucin-Limited Continuous Culture, Microbial Ecology in Health and Disease, 1:1, 31-38, DOI: $10.3109 / 08910608809140176$

To link to this article: https://doi.org/10.3109/08910608809140176

\section{( ) 1988 The Author(s). Published by Taylor \& Francis.}

\section{曲 Published online: 11 Jul 2009.}

Submit your article to this journal $\sqsubset$

Џ Article views: 753

Q View related articles $๘$

Citing articles: 58 View citing articles $\llbracket$ 


\title{
Enhanced Growth of Complex Communities of Dental Plaque Bacteria in Mucin-Limited Continuous Culture
}

\author{
D. A. GLENISTER* $\uparrow$, KATJA E. SALAMON*, K. SMITH $\ddagger$, D. BEIGHTON $\ddagger$ and C. W. KEEVIL*\$ \\ *Bacterial Metabolism Research Laboratory, PHLS Centre for Applied Microbiology \& Research, Porton Down, \\ Salisbury, Wilts. SP4 OJG. \\ $\ddagger$ Royal College of Surgeons, Dental Research Unit, Downe, Orpington, Kent BR6 $7 J J$.
}

Received 20 May 1987; revised 19 August 1987

The possibility that bacteria in plaque can grow at rates which are unaffected by the availability of dietary foods, because of their ability to metabolise salivary proteins, has been investigated by Keevil et al. using an in vitro continuous culture model. Plaque was collected aseptically from 13 school children, pooled and inoculated into a chemostat containing complex medium plus glucose. The principal genera enriched during growth at dilution rates of 0.05 and $0.2 \mathrm{~h}^{-1}$ (corresponding to mean generation times of 13.9 and $3.5 \mathrm{~h}$, respectively, which might occur in vivo) were streptococci (including Streptococcus mutans) peptostreptococci, lactobacilli, fusiforms, veillonellae and Bacteroides spp. Addition of $0 \cdot 1$ per cent $(\mathrm{w} / \mathrm{v})$ mucin resulted in an increased growth yield, due to increases in the numbers of anaerobes, but the recovery of peptostreptococci and veillonellae decreased. Importantly, Actinomyces spp. increased and the appearance of spirochaetes was noted in all cultures fed with mucin. Withdrawal of glucose from mucin supplemented complex medium resulted in decreased growth yield, the loss of Neisseria spp. and decreased recovery of streptococci and lactobacilli. Replacement of the medium with artificial saliva containing $0 \cdot 1$ per cent $(\mathrm{w} / \mathrm{v})$ mucin enriched for Bacteroides spp., but lower numbers of the other genera found in plaque were also maintained at both growth rates. This suggests that the chemostat can be used successfully to model the oral ecosystem, with salivary proteins providing the principal source of carbon and nitrogen for growth.

KEY WORDS-Mucin enrichment; plaque bacteria, mucin-limited continuous culture; enrichment of complex microbial communities.

\section{INTRODUCTION}

The antibacterial properties of saliva and its role in influencing the adherence of bacteria to teeth have been well established. ${ }^{15}$ However, little interest has been shown in either the growth of the oral microflora or the possible role of saliva as a substrate. Nevertheless, the rapid colonisation of bacteria on tooth surfaces in the absence of diet $t^{1,2,5}$ indicates that a continuous supply of nutrients, presumably the glycoproteins and proteins in saliva, can support the growth of the oral microflora. The few in vitro studies of oral bacteria grown on saliva ${ }^{31}$ or on agar medium prepared from human saliva, ${ }^{22}$ have provided supportive evidence towards this hypothesis. Cowman et al. ${ }^{11,13}$ reported that saliva could not

†Present address: Whitbread Breweries Research \& Development, Oakley Road, Luton, Beds. LU4 9QH.

$\S$ Author to whom correspondence should be addressed. serve as a sole source of nutrients for oral streptococci but that they could utilise specific salivary proteins as a nitrogen source. For the complex plaque microflora, however, it has been shown that the carbohydrates from salivary glycoproteins can be rapidly metabolised. ${ }^{3,12,32,33}$

Mucin is the principal glycoprotein of saliva and may therefore be an important growth limiting substrate for the complex plaque microflora. To test this assumption, it was decided to grow complex communities of dental plaque bacteria under a variety of continuous culture conditions in the presence and absence of mucin, including one environment in which mucin constituted the principal carbon and nitrogen source. Oral bacteria are continuously bathed by replenished saliva, making conventional batch culture studies irrelevant from an in vivo modelling point of view. However, continuous culture provides a constant supply of fresh medium, strict control of the growth rate and environment, 
and reproducibility. These attributes have been used successfully to model the various environments of the oral cavity and maintain complex communities of oral bacteria. ${ }^{19,24}$ In the present study, two dilution rates corresponding to mean generation times of 3.5 and $13.9 \mathrm{~h}$ were selected for investigation, since these relatively slow and fast growth rates have been measured at various sites in the oral cavity for bacteria growing in young or mature plaque. ${ }^{2,5,14,34}$

\section{MATERIALS AND METHODS}

\section{Inocula}

Plaque was kindly collected from 13 school children (aged 9 to 15 years) by Mr A. P. V. Pitter (Bath Dental Health Authority) and individual samples were immediately immersed in prereduced, serum-based transport medium ${ }^{7}$ under an atmosphere of filter-sterilised, high purity nitrogen. The samples were chilled in ice and transported to the laboratory where they were pooled in an anaerobic cabinet, dispensed into $0.5 \mathrm{ml}$ aliquots in $2 \mathrm{ml}$ screw-cap ampoules and stored in liquid nitrogen to maintain viability. ${ }^{36}$ The ampoules were removed from the liquid nitrogen, allowed to thaw slowly at room temperature and $0.45 \mathrm{ml}$ of the plaque suspension inoculated directly into the chemostat containing $500 \mathrm{ml}$ of medium. Continuous medium flow at the required dilution rate was initiated when the culture turbidity $\left(\mathrm{OD}_{540}\right)$ increased to greater than 0.5 (see later). The remaining $50 \mu \mathrm{l}$ of the plaque suspension was diluted in growth medium for identification and enumeration of the bacteria (see below). The composition of the inocula was similar to that described by Keevil et al. ${ }^{19}$ and varied little on prolonged storage in the liquid nitrogen, even after 18 months.

\section{Media}

The medium used for continuous culture, and as a diluent for viable counts, was the slightly modified BM medium of Shah et al. ${ }^{29}$ containing 0.5 per cent $(w / v)$ glucose as the limiting nutrient ${ }^{19}$ and supplemented with $5 \mathrm{mg} \mathrm{ml}^{-1}$ haemin and $1 \mathrm{mg} \mathrm{ml}^{-1}$ vitamin $\mathrm{k}_{1}$ (Sigma) to promote growth of Bacteroides spp. ${ }^{8}$ Alternatively, plaque bacteria were cultured in the defined saliva medium of Shellis $^{30}$ except that the principal glycoprotein, bovine submandibular mucin, was replaced with hog gastric mucin since this is not only cheaper but also is much more closely related to the human material than the bovine mucin. ${ }^{17}$ The porcine material was obtained as a crude commercial preparation (Sigma) and was purified by dissolving 10 per cent $(\mathrm{w} / \mathrm{v})$ in $0.1 \mathrm{M} \mathrm{NaCl}$, adjusting the $\mathrm{pH}$ to 7.0 with $\mathrm{NaOH}$ pellets and stirring overnight. ${ }^{27}$ The impurities were pelleted by centrifugation at $10,000 \mathrm{G}$ for $10 \mathrm{~min}$ and the dissolved mucin precipitated by adding ethanol to 60 per cent $(\mathrm{v} / \mathrm{v})$ final concentration. The precipitate was pelleted by centrifugation, as before, and redissolved in $0 \cdot 1 \mathrm{M} \mathrm{NaCl}$ before reprecipitation with 60 per cent (v/v) ethanol. This final, washed precipitate was lyophilised and stored at $5^{\circ} \mathrm{C}$ until required. Chemical analysis showed that the purified mucin was comprised of $(\mathrm{w} / \mathrm{w}): 37$ per cent hexosamine, 27 per cent total hexose, 10 per cent fucose, 20 per cent protein and 6 per cent neuraminic (sialic) acid (Beighton $e t$ $a l$., unpublished). This product has recently become commercially available in $50 \mathrm{~g}$ and $250 \mathrm{~g}$ quantities using our extraction procedure (product code 38105; BDH Ltd, Poole, UK) and gives essentially identical results to those described below. A 5 per cent $(\mathrm{w} / \mathrm{v})$ aqueous solution of mucin, $\mathrm{pH} 7.0$, was autoclaved at $121^{\circ} \mathrm{C}$ for $15 \mathrm{~min}$ and added aseptically to the remainder of the defined medium which had been previously sterilised by passage through a $0.22 \mu \mathrm{m}$ filter (Millipore). In several experiments sterilised mucin solutions were added to the BM complex growth medium, with or without glucose, to determine their contribution to the carbon supply of the culture and possible induction of mucin degrading enzymes.

\section{Cultural conditions}

The chemostat design was that described by Keevil et al. ${ }^{19}$ The medium was introduced into the $500 \mathrm{ml}$ of culture at a constant rate of 25 or $100 \mathrm{ml} \mathrm{h}^{-1}$ (dilution rates 0.05 or $0.2 \mathrm{~h}^{-1}$, respectively) to give mean generation times of $13.9 \mathrm{~h}$ or $3.5 \mathrm{~h}$, respectively. The $\mathrm{pH}$ was maintained automatically with $2 \mathrm{M} \mathrm{NaOH}$ and the temperature kept at $37^{\circ} \mathrm{C}$ with an external infra red lamp. The culture was grown anaerobically by surface gassing with filter-sterilised 5 per cent $(\mathrm{v} / \mathrm{v})$ carbon dioxide in white-spot (high purity) nitrogen (British Oxygen Company).

\section{Bacterial identification}

The microbial composition of inocula and in continuous culture was determined by isolation of serially diluted samples (in BM medium) on a variety of selective and non-selective media. ${ }^{19}$ Briefly, 
Table 1. Influence of dilution rate and medium composition on the yield of complex communities of oral bacteria growing in continuous culture at $\mathrm{pH} 7 \cdot 0$.

\begin{tabular}{|c|c|c|c|c|c|c|c|c|}
\hline \multirow{2}{*}{$\begin{array}{l}\text { Medium } \\
\text { Dilution rate }\end{array}$} & \multicolumn{2}{|c|}{ BMG* } & \multicolumn{2}{|c|}{ BMGM* $^{*}$} & \multicolumn{2}{|c|}{ BMM* } & \multicolumn{2}{|c|}{ Saliva } \\
\hline & 0.05 & $5 \quad 0.2$ & 0.05 & $5 \quad 0.2$ & 0.05 & $0 \cdot 2$ & 0.05 & 0.2 \\
\hline Culture turbidity $\left(\mathrm{OD}_{540 \mathrm{~nm}}\right)$ & $6 \cdot 5$ & 6.5 & $6 \cdot 8$ & $6 \cdot 8$ & $4 \cdot 1$ & $4 \cdot 4$ & $0 \cdot 5$ & 0.33 \\
\hline Yield (g dry wt. $\mathrm{L}^{-1}$ ) & $2 \cdot 5$ & $2 \cdot 1$ & $2 \cdot 75$ & $2 \cdot 6$ & 1.75 & $2 \cdot 18$ & $0 \cdot 32$ & $0 \cdot 23$ \\
\hline Apparent Yglucose (g dry wt. $\mathrm{mol}^{-1}$ ) & $90 \cdot 3$ & $78 \cdot 7$ & $99 \cdot 3$ & $96 \cdot 8$ & - & - & - & - \\
\hline Anaerobe conc. ${ }^{\mathrm{a}}$ & 6700 & 5800 & 7270 & 6505 & 875 & 1760 & 330 & 150 \\
\hline Aerotolerant bacteria conc. ${ }^{\mathrm{a}}$ & 3620 & 2807 & 1180 & 3895 & 765 & 212 & $6 \cdot 15$ & $3 \cdot 7$ \\
\hline
\end{tabular}

${ }^{*} \mathrm{BM}$ medium supplemented with glucose (BMG), glucose plus mucin (BMGM) or mucin (BMM). ${ }^{a}$ Denotes concn. expressed as colony forming units $\times 10^{-6} \mathrm{ml}^{-1}$. The results are the mean of triplicate samples with errors of less than 3 per cent for culture turbidity, 6 per cent for yield and $\mathrm{Y}_{\text {glucose }}$, and 15 per cent for bacterial concn.

these comprised 7 per cent (w/v) horse blood agar (Blood agar base No. 2, Oxoid) for total aerobic and anaerobic viable counts; horse blood agar supplemented with $2.5 \mu \mathrm{g} \mathrm{ml}^{-1}$ vancomycin (Sigma) for enumeration of Gram-negative bacteria and lactobacilli: the latter were resistant to this concentration of vancomycin and their identity was confirmed by growth on low pH Rogosa SL agar; TYC agar (London Analytical and Bacteriological Media) for streptococci and veillonella agar (Oxoid) for veillonellae. All plates, except those for aerobic bacteria, were incubated for 6 days at $37^{\circ} \mathrm{C}$ under an atmosphere of 10 per cent hydrogen: 10 per cent carbon dioxide: 80 per cent nitrogen (British Oxygen Company). Aerobic plates were incubated in a candle jar (effectively providing 5 per cent $(\mathrm{v} / \mathrm{v})$ carbon dioxide in air) for 3 days at $37^{\circ} \mathrm{C}$. Each different colony type was counted and representative strains subcultured onto blood agar. These were tested for the ability to grow aerobically and for catalase activity. Copious extracellular polysaccharide (EPS)-producing streptococci were defined as those bacteria producing either hard, rubbery, undetachable colonies (Streptococcus sanguis and Streptococcus mitior), or large, soft, gelatinous colonies (Streptococcus salivarius), on TYC agar containing 5 per cent $(w / v)$ sucrose. $S$. mutans gave small, irregular, crumbly, white colonies and was confirmed by the criteria of Hardie \& Bowden. ${ }^{16}$ Peptostreptococci were defined as obligately anaerobic, catalase-negative streptococci which grew on blood agar but not TYC agar. Veillonella, Actinomyces, Bacteroides, Eubacterium, Capnocytophaga, Haemophilus and Neisseria spp. were identified by the ability to grow aerobically or anaerobically, colonial morphology and appearance after Gram stain. Confirmation was obtained using the API Identification System. The presence of spirochaetes in samples was confirmed by dark field microscopy. Their viability was confirmed by growth on Spirochaete agar (Loesche, ${ }^{23}$ 1976). The samples were inoculated onto $0.22 \mu \mathrm{m}$ membrane filters (Oxoid) overlaid on the solid agar and the appearance of concentric rings of growth beneath the membrane noted.

\section{RESULTS}

The composition of the initial pooled plaque inocula was representative of that commonly stated in the literature ${ }^{25,26}$ and has been described previously. ${ }^{19}$ The complexities and interactions of the microbial consortia enriched at the relatively slow and fast growth rates which might be encountered in the oral cavity was reflected in the high culture turbidities and growth yields (Table 1). In particular, the molar growth yield for glucose was over $90 \mathrm{gdry} \mathrm{wt}^{\mathrm{mol}}{ }^{-1}$ in BMG medium at the slower growth rate, far in excess of the $35-50 \mathrm{~g}$ dry wt. $\mathrm{mol}^{-1}$ reported for pure cultures of oral bacteria growing in similar complex media. ${ }^{21}$ The lower growth yield at the faster growth rate was most probably due to decreased numbers of aerotolerant anaerobes (bacteria such as streptococci which are able to grow aerobically but which do not exhibit classical respiration and whose growth is not necessarily stimulated by oxygen).

The principal genera isolated from the homogeneously mixed cultures growing in BM medium supplemented with glucose were streptococci 
Table 2. Influence of complex and defined media containing glucose or mucin on the composition of complex communities of oral bacteria growing in continuous culture at a dilution rate of $0.05 \mathrm{~h}^{-1}$ and $\mathrm{pH} 7 \cdot 0$.

\begin{tabular}{lcccc}
\hline Medium & BMG & BMGM & BMM & Saliva \\
\hline EPS streptococci & ND & ND & 70 & $3 \cdot 7$ \\
Low EPS streptococci & 4100 & 1770 & 395 & $2 \cdot 8$ \\
S. mutans & ND & 10 & ND & $0 \cdot 5$ \\
Peptostreptococci & 2000 & ND & 25 & $2 \cdot 5$ \\
Lactobacilli & 96 & 110 & $0 \cdot 3$ & $0 \cdot 002$ \\
Actinomyces spp. & ND & 18 & 10 & $0 \cdot 6$ \\
Veillonellae & 580 & 10 & 10 & $2 \cdot 5$ \\
Bacteroides spp. & 300 & 5380 & 50 & 294 \\
Fusiforms & 220 & 7 & 45 & 26 \\
Neisseria spp. & $1 \cdot 6$ & 10 & ND & ND \\
Capnocytophaga spp. & ND & ND & $0 \cdot 35$ & ND \\
Haemophilus spp. & ND & ND & ND & $0 \cdot 02$ \\
Treponema spp. & ND & D & D & D \\
& & & & \\
\hline
\end{tabular}

The growth media were as described in Table 1 . Results are expressed as colony forming units $\times 10^{-6} \mathrm{ml}^{-1}$ and are the mean of samples from triplicate cultures with errors of less than 20 per cent. ND denotes not detected; D denotes detection of spirochaetes which could not be quantitated by the methods available.

(including the suspected aetiological agent of caries, $S$. mutans), peptostreptococci, lactobacilli, fusiforms, veillonellae and Bacteroides spp. (Tables 2 and 3 ). The aerotolerant bacteria, constituting a third of the total population, were predominantly streptococci and lactobacilli whilst the fastidious anaerobes consisted mainly of Bacteroides spp. and peptostreptococci. The numbers of some of the bacteria recovered decreased at the faster growth rate, particularly peptostreptococci, lactobacilli, veillonellae and fusiforms. By contrast, Bacteroides spp. increased 8-fold. EPS-streptococci, S. mutans, Actinomyces, Capnocytophaga, and Haemophilus spp. were undetectable at the slow growth rate but were present in high numbers at the faster growth rate. There was no evidence of viable or non-viable spirochaetes in the communities by growth on selective medium or direct microscopy.

Addition of 0.1 per cent $(\mathrm{w} / \mathrm{v})$ mucin to the complex growth medium resulted in an apparent increase in numbers of fastidious anaerobes in the complex communities at both growth rates (Table 1). This correlated with an approximately 10 per cent increase in growth yield and the apparent $\mathrm{Y}_{\text {glucose }}$ increased to almost $100 \mathrm{gdry} \mathrm{wt} . \mathrm{mol}^{-1}$. The observed population contributing to these increases was Bacteroides spp., while apart from spirochaetes,
Table 3. Influence of complex and defined media containing glucose or mucin on the composition of complex communities of oral bacteria growing in continuous culture at a dilution rate of $0 \cdot 2 \mathrm{~h}^{-1}$ and $\mathrm{pH} 7 \cdot 0$.

\begin{tabular}{|c|c|c|c|c|}
\hline Medium & BMG & BMGM & BMM & Saliva \\
\hline EPS streptoccocci & 215 & $3 \cdot 7$ & $17 \cdot 5$ & $0 \cdot 4$ \\
\hline Low EPS streptococci & 2555 & 3590 & $205 \cdot 5$ & $5 \cdot 6$ \\
\hline S. mutans & $1 \cdot 6$ & 0.65 & $0 \cdot 3$ & 0.002 \\
\hline Peptostreptococci & 510 & 260 & 85 & 0.65 \\
\hline Lactobacilli & 24 & 60 & $0 \cdot 1$ & 0.002 \\
\hline Actinomyces spp. & 4 & 95 & $26 \cdot 5$ & 0.7 \\
\hline Veillonellae & $17 \cdot 5$ & 11 & 50 & 3 \\
\hline Bacteroides spp. & 2515 & 3365 & 1200 & $135 \cdot 5$ \\
\hline Fusiforms & 7 & 3 & 95 & 4 \\
\hline Neisseria spp. & 4 & 0.55 & $\mathrm{D}$ & D \\
\hline Capnocytophaga spp. & 30 & 11 & 60 & ND \\
\hline Haemophilus spp. & 200 & $\mathrm{D}$ & 0.06 & $\begin{array}{ll}6 & 0.005\end{array}$ \\
\hline Treponema spp. & ND & D & D & $\mathrm{D}$ \\
\hline
\end{tabular}

The growth media were as described in Table 1. Results are expressed as in Table 2 with similar errors between samples. ND denotes not detected; $D$ denotes detection of either spirochaetes which could not be quantitated by the methods available or bacteria whose numbers were too low to quantitate $\left(<10^{2}\right)$ against the background growth of the predominant species on the agar media.

the remaining anaerobes were presumably less competitive in this particular growth environment and their numbers decreased (Tables 2 and 3). The numbers of aerotolerant bacteria only increased at the faster growth rate, while the addition of mucin promoted the enrichment of Actinomyces spp. which were previously very low in the complex BM plus glucose medium. It should be noted that spirochaetes were now detectable in the communities by either dark field microscopy or growth on the relevant selective medium.

The contribution of mucin to the carbon supply of the cultures was further ascertained by removal of glucose from the mucin supplemented BM medium. This growth environment resulted in a lower culture turbidity and growth yield (Table 1). There was an overall decrease in aerotolerant and anaerobic bacteria, with a more significant decrease in numbers at the lower dilution rate of $0.05 \mathrm{~h}^{-1}$, particularly Bacteroides spp. (Tables 2 and 3). These bacteria remained predominant at the faster growth rate but the slow growth rate favoured the growth of streptococci producing little polysaccharide on the relevant selective medium. 
Fusiforms, Capnocytophaga spp. and streptococci producing copious polysaccharide on the relevant selective medium were also enriched in the absence of glucose. By contrast, Neisseria spp. were only barely detectable when the glucose was removed.

Replacement of the complex growth medium with a defined, artificial saliva medium, again containing $0 \cdot 1$ per cent $(\mathrm{w} / \mathrm{v})$ mucin, caused a significant decrease in culture turbidity, growth yield and the numbers of aerotolerant and anaerobic bacteria (Table 1). Representatives of all the genera were detected in the complex communities growing in this medium, at either growth rate, with the exception of Neisseria and Capnocytophaga spp. (Tables 2 and 3 ). The former were only barely detectable at the faster growth rate. In contrast to members of the other genera, the numbers of Bacteroides spp. became particularly high in proportion to the total numbers of anaerobes. Furthermore, although difficult to quantitate, the numbers of spirochaetes appeared greatly enhanced when detected by either growth on selective medium or by direct microscopy of culture samples. The total numbers of bacteria in the communities were markedly different at the two growth rates. At a dilution rate of $0.2 \mathrm{~h}^{-1}$ the population size was half of that at the $0.05 \mathrm{~h}^{-1}$ dilution rate. This was a reversal of the situation found in the previous growth environments where the faster growth rate tended to sustain a higher population size.

\section{DISCUSSION}

Plaque is a heterogeneous system which is composed of a liquid phase containing salivary components, bacteria and their products: principally polysaccharides which retain the acidic products arising from the fermentation of carbohydrates adjacent to the enamel and cause its demineralisation (caries). The composition of the microflora within the plaque is extremely complex and it has been found to vary, depending on its site in the oral cavity and its age. ${ }^{25}$ Thus plaque can form at or beneath the gum (gingiva) margin and the altered communities are capable of causing inflammation (gingivitis) or tissue destruction and bone loss (periodontal diseases including juvenile periodontitis, rapidly-progressing periodontitis and refractory adult periodontitis). Previous studies have attempted to model the ecology of these diseases in the laboratory using a variety of batch or continuous culture techniques, and the latter have been laudable in attempting to investigate specific growth environments of physiological interest. However, these studies have usually utilised conventional complex media derived from animal sources with little regard for the actual composition of human saliva. As a consequence, members of the genera Actinomyces and Treponema are commonly found in the oral cavity but grew poorly or were absent in these laboratory studies, ${ }^{8,9}$ even after several further inoculations to promote a full enrichment culture. ${ }^{24}$

We have attempted to reconcile these difficulties by growing the oral microflora in continuous culture using the defined saliva medium of Shellis. ${ }^{30}$ This medium contains all of the principal ions found in saliva, together with the requisite low concentrations of amino acids, vitamins, albumin, alpha amylase etc. In particular, the medium contains bovine salivary mucin as the principal carbon and nitrogen source but this was replaced with purified hog gastric mucin. Mucous glycoproteins are characterised by a high carbohydrate: protein ratio. ${ }^{10,27,28,35}$ Much of the structural analysis has been on gastrointestinal mucins from non-human sources because of the difficulty in obtaining sufficient quantities from human sources. There is, however, no compelling evidence that the structures of cognate gastrointestinal mucins are grossly different. As a control, the complex BM medium was also supplemented with mucin to ascertain its effects in the absence of the other salivary components. The present results have indicated that either of the growth media which contained the mucin was able to support the growth of the previously fastidious Actinomyces and Treponema spp. over prolonged periods. The growth of Bacteroides spp. was also enhanced in the presence of mucin, particularly at the slow growth rate. The artificial saliva medium was also able to successfully support the growth of many of the principal genera found in the oral cavity. Interestingly, the established complex community was reminiscent of sub-gingival plaque which exists in anaerobic pockets of low redox potential and contains few aerotolerant bacteria. ${ }^{25}$ The latter included Haemophilus spp. which might have contained Actinobacillus actinomycetemcomitans, a species whose genus is currently in doubt. The strict anaerobes were dominated by Bacteroides spp. but also included spirochaetes, which appeared in great numbers although difficult to quantitate, and fusiforms. It is perhaps noteworthy that Bacteroides and Treponema spp., fusiforms and A. actinomycetemcomitans have all been implicated as causative agents of the periodontal 
diseases, ${ }^{25}$ suggesting that the present growth environment has potential for use in a suitable model system of those disorders. Furthermore, Actinomyces spp. have been implicated in a particular form of caries, root surface caries, ${ }^{25}$ and the present growth environment describes the first successful enrichment of members of this important genus in continuous culture. This finding supports the report by Bössman and Hoppe ${ }^{6}$ that Actinomyces spp. are enriched on saliva-containing agar media.

It is likely that alterations in the growth environment other than in medium composition, such as $\mathrm{pH}$, will also greatly affect the enrichment of particular species to model possible polymicrobial diseases. High numbers of streptococci, particularly $S$. mutans, and lactobacilli have been found in carious lesions and both grew successfully in the present study, albeit in comparatively low numbers. However, they, along with veillonellae, are the only members of a consortium enriched from plaque when the growth $\mathrm{pH}$ is similar to that of a carious lesion, namely $\mathrm{pH} 4 \cdot 0 .{ }^{9}$ Interestingly, a biofilm similar in composition to carious plaque is also formed when specific surfaces are immersed in the enriched culture. ${ }^{20}$ Future work will investigate the influence of environment on the composition of the biofilms associated with the range of dental diseases described previously.

The ability of a specific microflora to grow continuously in the artificial saliva suggests that members of that consortium were able to metabolise the principal carbon and nitrogen source, mucin. This has been confirmed by various means. Firstly, the mucin fraction recovered from the spent culture medium contained only 30 per cent $(w / w)$ of the original total hexose, fucose and neuraminic acid content and only 50 per cent $(w / w)$ of the hexosamine and protein content (Beighton et al., manuscript in preparation). Secondly, the consortium produced a range of cell-associated and extracellular exoglycosidases and peptidases capable of degrading the oligosaccharide side chains and protein backbone of the mucin, including high activities of fucosidases, xylosidases, glucuronidases, galactosidases, glucosidases, N-acetylhexosaminidases, sulphatase, and neuraminidase (Beighton et al., manuscript in preparation). Thirdly, many of these enzymes were either induced or produced by newly predominant species when mucin was included in the growth medium, especially in the absence of glucose. The ability of the putative periodontal pathogens to produce proteolytic enzymes has been described as an important virulence factor for tissue destruction. However, little attention has been made to whether some of these activities are directed at degrading salivary and crevicular fluid components for growth. Further studies will determine whether all of the requisite enzymes are produced by individual strains, such as the enriched Bacteroides spp. described here and elsewhere, ${ }^{4}$ or by the combined action of several strains.

In summary, the present study has described how mucin enriches for specific consortia during growth in complex or defined media. This will have profound consequences for developing laboratory media for the in vitro modelling of complex communities inhabiting other environments where mucin is prevalent. The structure of the glycoprotein used will also probably affect the composition of the microflora since in the gut there is a selection of bacteria that elaborate exoglycosidases capable of degrading the particular blood group substance secreted by the host. ${ }^{18}$

\section{ACKNOWLEDGEMENT}

This work was partly funded by a project grant from Warner-Lambert Co., Morris Plains, New Jersey, USA.

\section{REFERENCES}

1. Beckers H. J. A., Van der Hoeven J. S. (1982). Growth rates of Actinomyces viscosus and Streptococcus mutans during early colonisation of tooth surfaces in gnotobiotic rats. Infection and Immunity 35, 583-587.

2. Beighton D., Hayday H. (1986). The influence of the availability of dietary food on the growth of streptococci on the molar teeth of monkeys (Macaca fascicularis). Archives of Oral Biology 31, 449-454.

3. Beighton D., Smith K. (1986). The modulation of exoglycosidic enzymes in the supragingival plaque of macaque monkeys. FEMS Microbiology Letters 34, 319-322.

4. Beighton D., Smith K. (1987). Glycoprotein utilisation by an oral Bacteroides sp. Journal of Dental Research 66, 872.

5. Beighton D., Smith K., Hayday H. (1986). The growth of bacteria and the production of exoglycosidic enzymes in the dental plaque of macaque monkeys. Archives of Oral Biology 31, 829-835.

6. Bössman K., Hoppe W. F. (1967). Uber das vorkommen verschliedener mikrooganismen in der schmelzdeckschicht menschlicher zahne. Deutscher Zahn-Mund-Kieferheilkunde 48, 434-441.

7. Bowden G. H., Hardie J. M. (1971). Anaerobic organisms from the human mouth. In: Board R. G., Shipton, D. A. Isolation of Anaerobes. Society for 
Applied Bacteriology Technical Series No. 5. Academic Press, London, 177-205.

8. Bradshaw D. J., Dowsett A. B., Keevil, C. W. (1987a). A chemostat model for formation of bacterial films on acrylic tiles. In: Borriello S. P., Hardie J. M., Drasar B. S., Duerden B. I., Hudson M. J., Lysons R. J. (eds) Recent Advances in Anaerobic Bacteriology. 329-329.

9. Bradshaw D. J., Dowsett A. B., Keevil C. W. (1987b). Influence of $\mathrm{pH}$ and carbohydrate on plaque formation in the continuous culture biofilm model. Journal of Dental Research 66, 872.

10. Clamp J. R., Allen A., Gibbons R. A., Roberts G. P. (1978). Chemical aspects of mucus. British Medical Bulletin 34, 25-41.

11. Cowman R. A., Fitzgerald R. J., Schaeffer S. J. (1976). Role of salivary factors in the nitrogen metabolism of plaque-forming oral streptococci. In: Proceedings Microbial Aspects of Dental Caries. Special Supplement Microbiology Abstracts 11, 465-475.

12. Cowman R. A., Fitzgerald R. J., Perella M. M., Cornell A. H. (1977). Human saliva as a nitrogen source for oral streptococci. Caries Research 11, $1-8$.

13. Cowman R. A., Schaefer S. J., Fitzgerald R. J. (1979). Specificity of utilisation of human salivary proteins for growth of oral streptococci. Caries Research 13, 181-189.

14. Gibbons R. J. (1964). Bacteriology of dental caries. Journal of Dental Research 43, 1021-1028.

15. Gibbons R. J., Van Houte J. (1975). Bacterial adherence in oral microbial ecology. Annual Review of Microbiology 29, 19-44.

16. Hardie J. M., Bowden G. H. (1976). Physiological classification of oral viridans streptococci. Journal of Dental Research 55, A166-A176.

17. Herp A., Wu A. M., Moschera J. (1979). Current concepts of the structure and nature of mammalian salivary mucous glycoproteins. Molecular and Cellular Biochemistry 23, 27-44.

18. Hoskins L. C., Boulding E. T. (1976). Degradation of blood group antigens in human colon ecosystems. I. In vitro production of $\mathrm{ABH}$ blood groupdegrading enzymes by enteric bacteria. Journal of Clinical Investigations 57, 63-73.

19. Keevil C. W., Bradshaw D. J., Dowsett A. B., Feary T. W. (1987a). Microbial film formation: dental plaque deposition on acrylic tiles using continuous culture techniques. Journal of Applied Bacteriology 62, 129-138.

20. Keevil C. W., Dowsett A. B., Salamon K., Glenister D. A. (1987b). Effect of mucin on plaque formation in the continuous culture biofilm model. Journal of Dental Research 66, 872.

21. Keevil C. W., Williamson M. I., Marsh P. D., Ellwood D. C. (1984). Evidence that glucose and sucrose uptake in oral streptococci involves independent phosphotransferase and proton motive force-mediated mechanisms. Archives of Oral Biology 29, 871-878.

22. Leach S. A., Hayes M. L. (1967). Isolation in pure culture of human oral organisms capable of producing neuraminidase. Nature (London) 216, 599-600.

23. Loesche W. J. (1976). Periodontal disease and the treponemes. In: Johnson R. C. (ed) The Biology of the Parasitic Spirochaetes. Academic Press, New York, 261-275.

24. Marsh P. D., Hunter J. R., Bowden G. H., Hamilton I. R., McKee A. S., Hardie J. M., Ellwood D. C. (1983). The influence of growth rate and nutrient limitation on the microbial composition and biochemical properties of a mixed culture of oral bacteria grown in a chemostat. Journal of General Microbiology 129, 755-770.

25. Marsh P. D., Keevil C. W. (1986a). Metabolism of oral bacteria in health and disease. In: Hill M. J. (ed) Microbial Metabolism in the Digestive Tract. CRC Press, Boca Raton, 151-181.

26. Marsh P. D., Keevil C. W. (1986b). Environmental regulation of glycolysis in dental plaque. In: Leach S. A. (ed) Factors Relating to Demineralisation and Remineralisation of the Teeth. IRL Press, Oxford, 51-59.

27. Miller R. S., Hoskins L. C. (1981). Mucin degradation in the human colon. Fecal population densities of mucin-degrading bacteria estimated by a 'most probable number method'. Gastroenterology 81, 759-765.

28. Oemrawsingh I., Roukama P. A. (1974). Isolation, purification and chemical characterisation of mucins from human submandibular glands. Archives of Oral Biology 19, 615-626.

29. Shah H. N., Williams R. A. D., Bowden G. H., Hardie J. M. (1976). Comparison of the biochemical properties of Bacteroides melaninogenicus from human dental plaque and other sites. Journal of Applied Bacteriology, 41, 473-492.

30. Shellis R. P. (1978). A synthetic saliva for cultural studies of dental plaque. Archives of Oral Biology 23, $485-489$

31. Shiota T., Kunkel, M. E. (1958). In vitro chemical and bacterial changes in saliva. Journal of Dental Research 37, 780-787.

32. Smith K., Beighton D. (1986). The effects of the availability of diet on the levels of exoglycosidases in the supragingival plaque of macaque monkeys. Journal of Dental Research 65, 1349-1352.

33. Smith K., Beighton D. (1987). Proteolytic activities in the supragingival plaque of macaque monkeys. Archives of Oral Biology 32, 473-476.

34. Socransky S. S., Manganiello A. D., Propos D., Oram V., Van Houte J. (1977). Bacteriological studies of developing supragingival dental plaque. Journal of Periodontal Research 12, 90-106. 
35. Tabak L. A., Levine M. J., Mandel I. D., Ellison S. A. (1982). Role of salivary mucins in the protection of the oral cavity. Journal of Oral Pathology 11, $1-17$.
36. Wilson R. F., Woods A., Ashley S. P. (1984). Effect of storage in liquid nitrogen on the recovery of human dental plaque bacteria. Archives of Oral Biology 29, 941-944. 